\title{
A note on microscopy
}

\author{
F. J. AUMONIER \\ From St Mary's Hospital, London
}

The path of light rays through a typical vertical illuminator and the Ploemopak illuminator are shown in the Figures (Figs. 1 and 2; by courtesy of Messrs E. Leitz Ltd). In the latter, which is a development of the system used by metallurgists in the nineteenth century, the field diaphragm controls the size of the illuminated field. The exciter and barrier filters are available in four sets, which give a choice of different exciting and barrier filters which can be interchanged in a rotating turret. The beam splitter is also a dichroic filter which totally reflects the exciting wavelength but freely transmits the fluorescent light.

Address for reprints: Dr F. J. Aumonier, St Mary's Hospital, London W2

Received for publication 12 September 1978
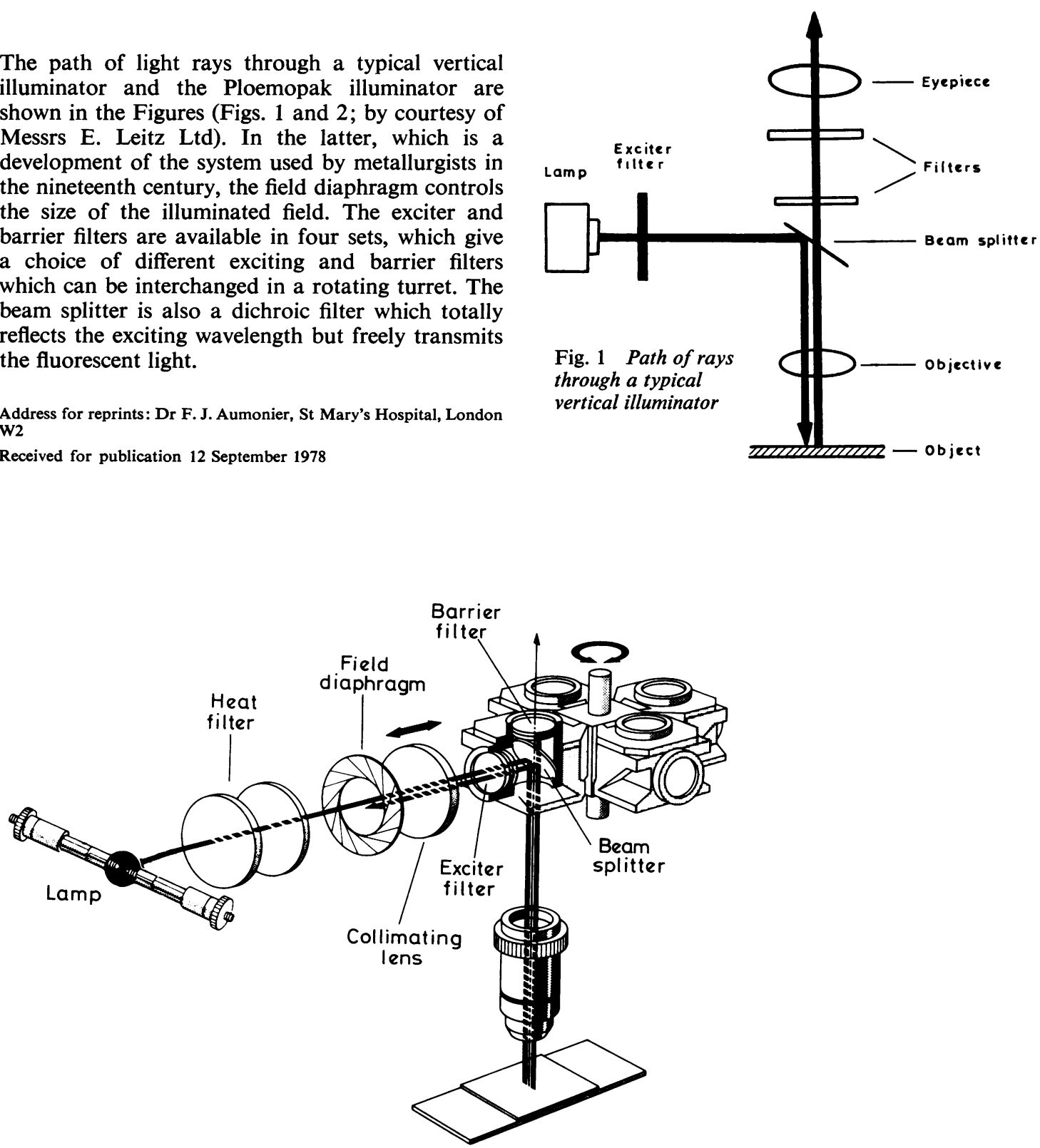

Fig. 2 Path of rays through the Ploemopak illuminator 